University of Massachusetts Amherst

ScholarWorks@UMass Amherst

Communication Department Faculty Publication

Series

Communication

2020

\title{
The Communicative Ethics of Racial Identity in Dialogue
}

Leda M. Cooks

University of Massachusetts Amherst

Follow this and additional works at: https://scholarworks.umass.edu/communication_faculty_pubs

\section{Recommended Citation}

Cooks, Leda M., "The Communicative Ethics of Racial Identity in Dialogue" (2020). Communication Theory. 115.

https://doi.org/10.1093/ct/qtaa007

This Article is brought to you for free and open access by the Communication at ScholarWorks@UMass Amherst. It has been accepted for inclusion in Communication Department Faculty Publication Series by an authorized administrator of ScholarWorks@UMass Amherst. For more information, please contact scholarworks@library.umass.edu. 
The Communicative Ethics of Racial Identity in Dialogue

\begin{abstract}
:
This paper explores the role of narratives about racial identity in constituting ethical performances in dialogue. Specifically, a dialogic communication ethics is described and placed in the context of intergroup dialogue (IGD) and communication approaches to dialogue. Then the focus turns to how these ethical frames and models for conducting dialogue functioned in a large-scale campus dialogue on race and whiteness. The paper addresses the ways identities were constructed and deployed in the dialogues by examining how dialogue topics are framed and discussed by facilitators and participants. This discussion of intention and outcome raises theoretical and practical questions in order to facilitate further conversations about identity and ethics in a controversially "Post-racial" era. Finally, the paper looks at how communication ethics and dialogue might work to address the discursive power of social group identities in pedagogical discussions of civility, inclusion, merit or a "good" life.
\end{abstract}

Keywords: ethics, intergroup dialogue, race, whiteness, identity 
The Communicative Ethics of Racial Identity in Dialogue

In the U.S., scholars, politicians, media pundits and social media influencers consistently observe that we live in uncertain and unstable times, our expanding populations and shrinking spaces made especially evident during the current global pandemic and mandated social distancing. We live with the differential impacts and consequences of increased mobility, diaspora, and displacement, climate change and gaps between rich and poor. In a country where the dominant cultural narratives of the good life clash with the diverse stories, values and cultures of daily interaction, we hear increasingly polarizing opinions about what is just, fair and equitable. Arguably, we live in an era where the nationalist narrative of loss of common values and a common people is a privileged nostalgia: a reminder that a dominant cultural group first has to assume they have their "commonness" to lose in order to experience a such "national" loss. For educators and scholars of communication, especially, our pedagogies, research and scholarship must not only recognize but engage in fundamental concerns of social life and social change (Artz, 2017). These concerns are-ostensibly-central to our largest disciplinary association. The Credo on Ethical Communication from the National Communication Association states: "Questions of right and wrong arise whenever people communicate. Ethical communication is fundamental to responsible thinking, decision making, and the development of relationships and communities within and across contexts, cultures, channels, and media" (NCA Credo). Into this moment, dialogue across difference in its many variations serves as both invitation and imperative for social justice and democracy to flourish. 'The question [for an 
engaged populace] is what living a "good" life or being a "good" person looks like in a time of narrative and virtue disagreement' (Arnett, Fritz and Bell, 2009, p. 3).

Dialogue, as the equitable sharing of selves and others toward understanding and connecting around differences, has been idealized and politicized as the image of justice (Buber, 1955; Peters, 1999). But dialogue also can create and/or maintain unequal relations of power. Wood (2004), Buber (1955), Arendt (1978), Freire (1972), among others, have raised concerns about dialogue that is forced, inauthentic or based on power inequities. Dialogue across and about social and cultural differences will always involve power dynamics and the politics of persuasion, and so ethics and dialogue are always intertwined. But what is the ethical position of dialogue? Or more specific to the purpose of this paper, what communicative practices in dialogues about race and racial identities protect and promote our (culturally located) visions and values for living a good life? I raise these theoretical and practical questions to facilitate further conversations about identity and ethics in a controversially "Post-racial" era. More specifically, what are the ethical implications of approaches to intergroup dialogue focused on race? How are the topics to be discussed framed and addressed by facilitators and participants? And lastly, how might a communication perspective on dialogue work in conjunction with other approaches to address the discursive power of social group identities in pedagogical discussions of civility, inclusion, merit or a "good" life? This paper attempts to provide both conceptual and practical responses to these questions. I want to think through the ways we might approach ethics in dialogic pedagogy and facilitation, and to better understand the impact of ethical stories on 
participants in dialogues about race and identity. To this purpose, I explore the role of narratives about racial identity in constituting ethical performances in dialogue. As a theoretical foundation, I first discuss dialogic communication ethics and then place these ideas in the context of intergroup dialogue (IGD) and communication approaches to dialogue. My interest is in how the different models for dialogue destabilize the narratives of self and other, us and them, that form the background of struggles for social justice. Lastly, the focus turns to how these ethical frames and models for conducting dialogue functioned in a large-scale campus dialogue on race and whiteness. In particular, I focus on the facilitation model for two dialogues that asked students to locate themselves within different discourses on whiteness that emerged in their own talk in the previous session. Although the dialogues I discuss occurred over a decade ago, I have continued to use these facilitation models, on a smaller scale, in campus, high school and other community contexts. Also, these approaches to interracial dialogues remain widely used and promoted by Teaching Tolerance, Campus Compact, National Coalition for Dialogue and Deliberation and other organizations promoting dialogues for social justice. I contend, then, that there is much to be gained by examining dialogues on whiteness in consideration of the contemporary atmosphere of increased polarization of beliefs about racial and political identities.

Communication Ethics and identity Communication ethics... requires one to watch and learn-dialogue begins with attending to what is before us, not what we demand in the moment or the Other, our partner in discourse, to provide for us (Arnett et al. 2009, p. 5). 
Communication ethics is premised on the idea that all communication has an ethical dimension which does not lie in abstraction but in the everyday practices that place us in relation to others. As Arnett et al. (2009) explain, communication ethics "carries or reflects two sorts of related goods. The first is a substantive good that we want to protect and promote. The second is a set of communicative practices that ensures active protection and promotion of a given good" (4). While defined variously, "goods" in Western philosophy have been described as those things (people, nonhuman animals, objects, actions) that are valued in the pursuit of happiness, quality, or excellence in our lives. Substantive goods give guiding force to our actions, although they do not ensure that we will always act in accordance with those goods. Ethics are expressed in the degree of difference between the ought to do or should do that sustain our cultural locations and our actions within or outside of those frameworks. In this manner, we both constitute and reflect our identities through our stories of the good, and these narrative goods often contradict the narrative goods outside of our cultural identity positions.

Holding narratives of identity and the "good" in tension within and across cultures should not discount the fact that people must go on living together despite these tensions. Nor should it ignore the tendency to dichotomize good and bad, moral and immoral within our own enactments of the "good." Ethics resides in our practices, but we also must be capable of reflection together on those practices to identify what is a good life lived together. In short, we must act as a witness to our own and others' responses. Arnett et. al (2009) note that, "[such] decisions hold implications for human lives. Communication ethics requires continual deliberation; it is not for the faint of 
heart nor those satisfied with easy answers" (31). A communicative approach to ethics constantly asks why it is we value what we do and how we go about enacting these values. It is concerned with both the philosophical reasons behind our actions (systems of values and beliefs) and the application of those "goods" in everyday life.

Discussing the communicative ethics of diversity in higher education, Allen (2013) notes that such an approach first requires laying the groundwork through the pervasive discussion of valuing difference across the (institutional) communication environment. This information must, however, be accompanied by tools for students, faculty and staff to engage in discussion about what has been, is currently and is to be valued. Allen (2013) advocates dialogue, stating that, "Participants might entertain such questions as: "What are the criteria for determining rightness and wrongness? What values ought to guide decisions? Who will benefit from decisions? And what will the impact be for certain groups, individuals, the institution, or society as a whole?" (19). Within the discipline of communication, discussions about the academic, disciplinary and institutional valuing of knowledge and labor have recently been raised publicly for scrutiny. It is instructive to ask how these terms become meaningful across academic contexts as well as the communicative ethics underlying calls for in/ civility or for revaluing merit, among other issues.

While communication ethics is rooted firmly in the Western perspectives and biases that define both "communication" and "ethics," it offers a reflection on the communication of and about whiteness and cultural privilege that can be useful when considering dialogue across differences in the US. As a white, educated, middle-class woman who places high value on equity and community, I endeavor to be inclusive in 
my teaching, facilitation and interaction with others. My own desire for inclusion is based in experiences of inclusion based on my social group identity and the legal, economic, social and educational assets that accrue with that privilege. That desire also comes from experiences of exclusion and in/difference that have shaped my life. As a dialogue facilitator, I realize that inclusivity is an ideal, for as long as power is in play so too is language that differentiates us regardless of our identities. From this standpoint, identity, equity and difference cannot be fully accounted for in social group identities. While social groupings may tell us much about embedded difference, privilege and oppression, they cannot always explain the ways power flows in moments of interaction with another. Communication opens us to the possibility of difference, and discourses and performances of identity are the creation and manifestation of the continual openings and closings of meanings.

\section{Responsibility, choice and discernment in dialogue}

In this paper, I make connections between stories about racial identity, the enactment of those stories and their facilitation in dialogue. I do so to point out the ways stories might be held up for scrutiny and attention to better reflect on the ways responsibility, choice and discernment are interpreted across ethical cultural positions (Arnett et al. 2009). These three themes run throughout the story of communication ethics as it has developed in the U.S. and are fundamental to calls for and the performance of intercultural dialogue. Responsibility and accountability can be expressed in one's description and expectation of what is good and valued, not only through recognizing, but in responding to the other in-relation-to the self. NcNamee and Shotter (2004) ask the question: "How do we do this together? My actions alone are not whol- 
ly mine. They are ours. They are responsive to the situated moment, to our traditions of discourse and to our imagined futures" (p. 104). Responsibility here literally becomes response-ability or our ability to respond to the other as if they were us and vice versa. Of course this does not mean forsaking one's own stories of the good life simply because they differ, but in recognizing the place or absence of the other within our communicative practices of the good. For instance, in the meritocratic system of the U.S., where we claim that everyone has an equal choice, we must acknowledge that these choices are positioned and enacted within a system created by the dominant group, and thus are inclusive of the standards that most benefit that group. Here, responsibility and accountability must exceed the system of choices made and accountability to the values that perpetuate the dominance of one group over others. To be responsible is to be responsive to the differences that are inherent in social life as opportunities for learning. Indeed, for Arnett et al. (2009) learning is the essential principle of communication ethics. Learning orients us not in habit and expectation but in possibility. McNamee and Shotter concur: 'We should not be concerned with asking, "how did we get here?" but rather be interested in asking, "how can we get there?"' $(2004 ; 104)$.

Choosing from among various stories of the good requires that we educate ourselves as to what stories exist beyond those with which we have become comfortable. Choice is imperative to freedom in stories of the good, but choices have consequences which also beget their own "goods." Thus, each ethical decision requires discernment of how the narrative good is enacted within a particular life circumstance (Benhabib, 1992). Extending the example above, discernment in meritocracy (for 
members of dominant groups) means, as Miller (2019) argues, acknowledging that interacting with exclusive systems of merit "may also be painful for members of marginalized and oppressed groups, but it is also the only definition of success many of us have known" (79). Discernment requires of us the ability to "distinguish the fine nuances between the source, substance, and effects of our responses" in discussions of race, power and privilege, and to be painfully honest with ourselves in doing so (Berila, 2016; 133).

Dialogues that focus on topics of racial identity and whiteness on predominantly white campuses in a cultural milieu that rewards individual success over collective effort may therefore invite resistance. Talking about how our various intersecting identities may position us as already several rungs up or down the ladder means acknowledging our vulnerabilities and/or sense of entitlement. But resistance may itself be a response to several contrasting narratives of what is good ethically that posit the acknowledgement of racial difference as a remarkably immoral act. This sometimes visceral response to language that points toward (and not away from) racial identity is often portrayed as an emotional and defensive shutdown to dialogue. Yet, resistance can also be an ethical response to perceived inequality based on dominant cultural stories of colorblindness and individuality as virtuous. Warren (2003) and Yep (2007) observed the tendency on the part of many of their white students to offer individual solutions to structural problems of racial inequity. In discussions about race and difference, students often pointed to individual behaviors that should be changed to reflect white cultural norms, rather than how the cultural norms are reflected in legal, economic, social and cultural institutions (Warren, 2003; Wise, 2010). Nonetheless, 
the students' solutions might become an opening to understanding how standpoint and narrative work together in constructing whiteness as a group narrative of individual choice over identity.

\section{Dialogue Models}

\section{Intergroup Dialogue}

Intergroup dialogue (IGD) scholars have placed conversation about identity and its relationship to social group (in)equities at the heart of education about self and other, community and difference. Intergroup dialogues have focused on the goals of social justice and improving intergroup relations on college campuses (Rodriquez, Nagda, Sorenson \& Gurin, 2018). Several parameters separate IGD from other forms of dialogue (e.g. learning circles, public conversations): Co-facilitators lead the dialogues, which involve participants who come from two or more social identity groups, occur over a sustained period of time, in a structured context. The dialogues are described as an opportunity to learn about each other and to learn skills and tools to help listening across differences and promote productive conflict. IGD presumes that, although participants engage in dialogue voluntarily, some degree of power balancing must occur (Zuñiga, Nagda, Chesler, and Cytron-Walker, 2007). IGD’s focus on the inequities that allow for the privileging of some identities and the marginalization of others often means a structured approach to the process of dialogue-a process in which participants are encouraged to identify with particular social group identities in order to better examine the power (or lack thereof) contained in those positions (Chesler, Lewis and Crowfoot, 2005). 
Intergroup dialogue, while careful to promote engaged conversation, emphasizes dialogue as a noun: a forum or space in which people can suspend judgment to focus on justice. As a noun, dialogue should be a container for ethical interaction, necessarily set apart to create the conditions for equitable relations not (immediately) achievable in the outside world. For IGD practitioners working across social groupings, the safety of the space is paramount and necessary if participants are to address one another as equals and equally vulnerable. Therefore, for instance, participants may be included or excluded based on their level of racial identity development (Helms, 1995).

The IGD approach to dialogue tends to assume that identity construction resides in individuals, that some level of racial identity awareness has been attained, and that communication in the dialogue may be controlled through participation based on identified social group identities and individual identity development. Ethical "goods" in IGD come from acknowledgement of one's own and recognition of others' identities. Still, facilitation models that frame behaviors as predetermined by social group identities and thoughts formed through individual cognitions may run the risk of solidifying the solipsistic aspects of group identification. Here, a student may become more fully aware of their level of racial identity development, but connecting through and in difference may feel impossible or, at the least, overwhelming.

\section{Relational or communication approaches to dialogue}

For many scholars interested in dialogue and discourse, the frustration and magic of communication is that it cannot be fully predicted or contained, and that efforts to design social interactions cannot ensure safety of the process or achievement 
of the desired outcome (Peters, 1999). While all scholars and practitioners of dialogue advocate communication that promotes the public good, a communication perspective on intergroup dialogue differs from IGD in that the format is not often structured to advance an already agreed-upon narrative of power, identity and difference, though a common goal of equity and social justice may be promoted. Rather, from a communication perspective, the emphasis is on a kind of narrative "commons" where the dialogic nature of communication might be reflected and engaged relationally. Here, McNamee and Shotter (2004) observe that,

if we believe that we are autonomous beings, each equipped with our own, private abilities to represent reality accurately then... we approach our everyday engagements as if each participant either knows or does not know, can do or cannot do... On the other hand, if we take seriously the relational sensibility required of dialogue we would probably enter into the mundane activities of our lives in very different ways. We might, for example, enter into a conflict with curiosity about how it emerged and what purpose it was serving rather than from the perspective of why it was occurring and who was at fault. (102)

An approach to dialogue that emphasizes openness, not only in the sharing of one's own views and listening to others, but in openness to creative potential of interaction, might displace the certainty with which we understand our positions as our own and promote a curiosity about the other that ties it/us/them to an essential being. We can become curious about language. How did I come to describe myself in this way? How do I differentiate my stories about identity from the others I hear in dialogue? While an openness to others' social and cultural group identities is often fore- 
grounded in intergroup dialogues, a curiosity about language and its relationship to our stories about selves might displace essentialized constructions of race. Race and power, then, are dynamically intertwined and embodied through discourse and performance.

Although different emphases (as noun, verb, individual cognition, social/relational construction) and contexts (located in space or in language) for approaches to dialogue exist, each can inform the other. In the IGD model of dialogue, ethics are rooted in the recognition of marginalized (targeted) identities and the re/distribution of justice. When the relational aspects of communication and dialogue are highlighted, we might see the ways identity, while embedded in structures that privilege some groups over others, is also created relationally and our narratives about how as well as what difference means can change, merely in the course of humans interacting. These ideals are at root about relationships, and pose the basic philosophical and ethical question: How/should we be accountable to others? In the sections that follow, I illustrate how we worked with these questions and concepts to put ethical stories of racial identity and whiteness in play with one another in a large-scale campus dialogue series on race and whiteness.

\section{Analysis}

\section{Dialogue description and procedures}

The dialogues were entitled, "How does race matter? Dialogues on racial identity and whiteness," and were conducted in the fall semester of 2009 on the campus of a large Northeastern university. The naming of the dialogues led to a dialogue amongst myself and the facilitators over whether and how the name might serve as an invita- 
tion to engage, provoke weariness, dismissal or resistance. We designed the dialogues an address to all students to discuss the dynamics of race on our campus after the election of Barack Obama to the presidency of the United States. Our hope was that the dialogues would focus on the ways that whiteness as a set of power relations served as an organizing principle for intersectional identities as well as structural racial inequities.

Of the 430 undergraduate students who participated in the dialogues, 214 identified as white, Irish-American, or Italian American, 74 identified as African American, black, Jamaican, Haitian, Cape Verdean and African (e.g. Ghanaian), 35 as Latina/ o/x or Dominican, and 30 as Asian American or Asian. Approximately one quarter of the participants identified themselves as international students. This national difference was significant in dialogues that featured racial identity, since being identified as raced was a new phenomenon for many of these students. The gender distribution of the dialogues was reflective of the university as a whole, with @60\% identifying as female, $35 \%$ as male and 5\% choosing other identifications participating. The average age of student participants was 20 years. Other identity markers such as sexuality, class, and ability were not assessed.

105 groups of students participated in three dialogues over the course of the semester, with the option of joining a fourth dialogue filmed on cable access television the following semester. The dialogues combined an IGD format for discussions of social identity and social justice in the first dialogue with a communication approach to the discourses and performances of whiteness in those that followed. Borrowing from the IGD model, the first dialogue began with a description of social group identity cat- 
egories, and locations within those categories as a basis for discussing intersectional identities and differing narratives about race. After each of the first three dialogue sessions, students and facilitators completed a one-page response paper, indicating their thoughts about the process and feelings about the discussion taking place as well as suggestions for future dialogues. From the discussion and responses to the first dialogue, we (facilitators and myself) looked at the narratives created as a basis for approaching those that followed. We felt that each dialogue could provide us with positions from which to construct webs of narrative relationships-stories of difference and what "goods" were worth protecting and preserving. Due to scheduling complications, we were unable to duplicate the participants or facilitators for each dialogue, so we endeavored to make connections across dialogues. In the remaining sessions, we combined standpoint and narrative theory, asking students to locate themselves in relationship to the stories told by their colleagues in the previous dialogues. Although there is much that could be discussed about the data collected as part of this project, the focus of the next sections is on the performance and praxis of ethics in the framing and facilitation of the dialogues. For this reason, as well as space considerations, only the first two of the four dialogue sessions will be considered in this paper. The first dialogue: Recognizing identity

As mentioned, the first dialogues started with identity formation and the development of social group identities (e.g., race, class, sexuality, gender, language, etc.). Then, we ${ }^{1}$ discussed the performative and discursive usefulness of these identities as well as contingencies and contexts for power. Most students learn about social group identifications long before they come to our campus, and we wished to emphasize the 
various contexts for identification and the ways power might be dis/embodied as dominant, (other than) normal, natural or marginal. Rather than continuing to locate identities in static categories of social groups, we felt it was important to understand the relationship between the performance and communication of identities. Through various exercises, participants were asked to identify aspects of their personal and social group identifications that stood out for them on campus, in the local town, at home, etc., and those that felt less recognizable or important. In the first dialogue, as well as those that followed, participants moved back and forth between activities in smaller groups followed by discussion in the larger group. At the end of each dialogue the students and facilitators completed response papers.

Dialogues with an explicitly social justice agenda promote an ethics of recognition, both of social group identities marginalized in mainstream society and the distribution of power accorded dominant groups. They further promote the good of storytelling itself, although the telling of and listening to others' stories must conform with the frame and format of the dialogue (ground rules, structured activities, focused on experience). Responses gathered from the first dialogue indicated a good deal of resistance to the introduction of the concept of social group power and position. In their reflections, several of the participants articulated some confusion and concern over what "good" might come from drawing attention to a topic that seemed to cause conflict and distress. Some white students indicated that any discussion of race made them feel like people thought they were racist. Others observed that we were talking about a subject that they felt had already been dealt with through the election of President Obama. For some students of color, likewise, talking about race with white peo- 
ple and/or other students of color had the potential to reopen old wounds, and wellintended dialogues sometimes made the situation worse. One student of color, for instance, discussed his ambivalence about the good that might come from discussing his feelings of invisibility in the classroom as balanced by the grief that could come by acknowledging those feelings. Since some of the students who participated in the dialogues may have done so to avoid an alternative assignment in their class, we did not assume willingness or eagerness to discuss the topic, regardless of racial identification. The choice to engage in dialogue was one of several options; the attractiveness of these options impacted the degree to which students were initially open to the discussion.

Participation in an actual dialogue on the topic of racial identity and social justice (rather than arguments, debates, graded assignments, viewing media, etc.) was reportedly a new and unusual experience for most of the students, and most white students likely had never been asked to reflect deeply on their own racial identity, its impact on their own lives as well as in-relation-to others. ${ }^{2}$ Indeed, the fact that embodiment dictated whether they could "walk away" from or simply not think about race seemed to surprise many white students. This lack of experience in speaking reflectively about racial identity was often expressed as not knowing the "right" thing to say in any context, much less to people of color. Often, it seemed, concern that they appear non-racist outweighed the desire to better understand their own and others' racial experiences on a predominantly white campus and in a racialized society.

Indeed, lack of self awareness and racial identification is the main reason IGD practitioners prescreen potential participants, using racial identity development as- 
sessments and other measures designed to include only participants with more developed awareness of the structural and personal dynamics of racism, listening skills and a wish to combat racism (Zuniga, 2010). While certainly we too had concerns about the vulnerability of students of color, we believed that there was also power in the dialogue process itself, and that if we trusted in that process and guided students through it, they might begin to have more thoughtful and helpful conversations about race within and across groups.

We recognized the potential for harm and injustice, but felt equally that not all resistance was malicious or ill-intended, and that there was an ethical calling and educational need to recognize and articulate what it means inter/personally to go through life as a person with and seemingly without a racially-identified body. Since the campus and local community is predominantly white, we felt that the dialogues could also be a space for students of color to participate in discussion about how whiteness shapes power and oppression in their experiences navigating campus and their lives (for facilitators' view see Herakova, Jelaca, Sibii and Cooks, 2011). Freire (1970) writes about how the disenfranchisement and disregard of students leads on the one hand to helplessness and disempowerment, and on the other to uncritical forms of resistance that can work against their own interests. We realized that all students likely experienced some degree of vulnerability in these discussions and that we needed to recognize their feelings as valid, given their relative standpoint. We wanted to engage resistance from a communication ethics position, and so used the stories gathered from the reflections to offer particular standpoints on stories of what is "good" communicative behavior. We then offered these stories/standpoints for students to 
put into dialogue with one another. We were interested in texts that framed resistance as a sequence of choices that required students' response-ability and discernment in light of the goals of social justice.

The second dialogue: Choice and the communicative ethics of identification

For these reasons, the second dialogue utilized a communication-based approach to design (e.g., Pearce \& Pearce, 2001), and used students' responses as a springboard for further discussion. After meeting with facilitators, talking to course instructors, and going through the response papers from the first dialogue on social group identity, it seemed that there was a need to discuss the strong emotions that emerged from talking about their experiences of social group and, in particular, racial identification. Therefore, we decided to separate students into affinity groups, with the added dimension of having them choose those affinity groups and reflect on the choices made and not made.

To prepare for the upcoming discussions, the following instructions were sent to the participants:

\section{Dear Dialogue Participants,}

Thank you for your enthusiastic participation in "How does race matter? Dialogues on race and whiteness" project. This second round of dialogues will focus on race as it relates to whiteness and white identity for all people, regardless of racial identification. The format for this second dialogue will differ from the first. Upon entering the room for the dialogue, you will be asked to sit with a group with which you identify racially. Please keep in mind that the choices for this selection are not all that they should or could be, but are categories based on some clear differences in life experiences with race on campus, in the United States and elsewhere. Our hope is that you will be able to express ways with which you identify or do not with the group or with the category as part of our discussion. 
In the conference room where the dialogues took place, tables were set up with signs that read "non-ALANA33, domestic/US students," "white, international," "ALANA, domestic/US", "students of color, international." At the door, several facilitators were stationed to help guide students through the process of choosing where to sit. More tables and spaces for different groups had been planned, but space and facilitator schedules limited our ability to provide more choices. The (admittedly confusing) differentiations in labeling the groups was deliberate in calling attention to what was foregrounded or backgrounded in our labeling, and facilitators were tasked with discussing these choices with the groups. Some students headed straight for a group without deliberation while others stood in the doorway and debated staying or leaving. Still others asked me or other facilitators where they should sit. Some sat with their friends in solidarity, while others sat with a group that physically looked different from them, perhaps as a point of moral contention with the "forced choice" of identification. Our discussions with the groups about the reasons behind their choice of seating served as a bridge to our larger purpose in the second round of dialogues: to talk about the power and inequities of social group categories and about whiteness as an organizing structural force.

An interesting and important by-product of the process of literally situating oneself in the dialogues was that white students asked to choose affinity groups in the second dialogue expressed that they could not learn about race from other white people. ${ }^{4}$ Although this commonly expressed sentiment is in line with the benefits of multiculturalism and diversity in education, it once again distances white people from their own racialized bodies. The assumption that white people can only learn about 
race from people of color presupposes whites have no knowledge of the workings of whiteness, race or power, and places the burden of teaching white people once again on people of color, even as the students have exploited and co-opted their teachers' identities.

Applying the three communication ethics themes of responsibility, choice and discernment, we can see that students were asked to be accountable for their racial identification (presence) to others in the dialogues. For some students such a choice was already political, and not necessarily one of identities but rather a choice in terms of alliances. For others, being asked to choose a group identity was a limitation on the ethical good (freedom) of individuality. The moment of choice itself was emotional for many students - a breaking down or reinforcing of social categories of identity and difference in an assumed (for white students) "post racial" place that had embodied consequences in this space, this moment. The discernment of the value of ethical goods inherent in the choices made was not immediately apparent, but unfolding in the course of our conversations in this dialogue about stories of resistance to racial identification.

After the affinity groups were seated and introductions and check-ins completed, facilitators passed around the following document, altered for each group based on their racial group identities:

After our last dialogue, we received responses that ranged from resistance to engagement on the topic of race, and especially to the concept of whiteness. We would like for you to look over some of the responses with a partner to discuss times where you may have felt similarly or differently. If you have experienced these moments, what did it feel like? How do you feel now when you recall it? Do you have a different response?

Responses expressing resistance to discussing race and whiteness: 
1. Silence: If this happens for you, what are some reasons for silence?

2."Times have changed. There is equality in our society now. Race is not an issue."

3. "Yes, racism exists, but anyone from any group can be racist."

4. "No one wants to talk about reverse racism, but it exists. My uncle, (aunt, brother, friend, etc.) was applying for a job. They scored higher on the entrance exam, (had more experience, etc.) than the other applicant of color. The person of color still got the job over them."

5. "These are personal stories (of privilege or oppression)." “One person's story is their own experience and is not as valid as the facts."

6. "I treat everyone the same. People are the same no matter what their race or ethnicity."

7. “I don't feel like a victim because of my race, so I don't feel the need to talk about race, and racism."

8. "If I express any pride in the things white people have done, then people will call me a racist."

9. "I do not want to hear from ignorant white people who dismiss the fact that this country was built on the oppression of my people."

10. "As a person of color, I am tired. I feel like my identity is used as a story, but what do I get in return?"

We used the responses above, gathered from student reflections on the first dialogue, as an opportunity for students to discuss the ways their identities might be reflected or displaced in these statements, and how resistance, language and power intersected in different ways for different bodies.

Examining the handout above through the ethical themes of responsibility, choice and discernment, it becomes clear that we are asking students for their response-ability to a topic that we acknowledge provokes defensive reactions. How can they be responsible for the knowledge that they, together with their peers, produce about their collective racial identities? In the second dialogue we asked students to position themselves within, around or against narratives that they had produced in response to the first dialogues. We did not regard these as permanent positions but as choices made to affiliate with particular stories of the good. Discernment, then, hap- 
pened in the process of reflecting upon a range of narratives that represented complicated and intersecting locations of social group power. Who could or should talk about race, with what knowledge, in what contexts and with what consequences? Moreover, what conversations and codes could or should people of differing racial identities participate in, and under what conditions? During the dialogues, white students consistently questioned if there were circumstances under which they might be able to use the " $n$ " word. On a book tour Ta-Nehisi Coates (2017), responding to a similar question, talked about the ways language reflects group status. White people, because they occupy privileged racial status, assume that they can use the in-group language of other groups with impunity. We asked white students who raised the n word question to reflect on what such limitations on participation might mean to nondominant groups who experience constant linguistic and cultural marginalization or exclusion in interactions with white people.

The "How does Race Matter?" dialogues framed open discussion of difference, marginalization and privilege as imperative, but within that ethical frame some stories held more credibility than others. Stories about the experience of race seemed inevitably to place authenticity on the bodies of students of color. In other words, the good that was protected and promoted in recounting one's experience of racial identity tended to solidify author credibility based on skin pigment. The equation of whiteness as the absence of race was compounded by the authenticity accorded stories of racial identity. Our (the facilitators and my own) attempts to open up these narratives to scrutiny as constructions that (re) created and legitimized whiteness meant also recognizing and discussing the ethical stories that gave force to visions of the good. 
These stories tended to presume equality in the face of evidence that indicated otherwise. Equality here meant that the burden of race was held equally across social categories, but the stories of white students: stories of not identifying with a race, stories that placed racism on individual actions without including social/institutional systems, stories that assumed that all things racial referred to people of color, erased white bodies from a disembodied equation of justice.

White students socialized into a world of racial acceptance and the goods of equality, individualism and meritocracy will quite naturally defend the goods promoted in those narratives; after all, these are values often taught as universal (Jackson II \& McDonald, 2019). They might easily see narratives that threaten whiteness as universally disruptive and as attacking their personal morality. Instead, we asked students who affiliate with dominant groups to focus on what they might learn from the whywhy are these "goods" different—and how we might go on to learn from these differences?

Students of color had different responses and responsibilities to whiteness and to the resistance narratives posed in the handout. ${ }^{5}$ Some students dismissed the dominance of whiteness as a social, political, economic and cultural force, and instead voiced the importance of their personal narratives of hard work and achievement over group struggles for equality. Other students resented the "race card" and the victim status associated with it. The choice to see themselves as subjects of their own stories, able to transcend any barriers placed before them allowed an identity to emerge that was not seemingly as interconnected to a group narrative. Another "good" voiced by a student of color and not challenged in his affinity group was the privilege associated 
with stereotypes. His height, stature and racial identification as a black man afforded him the opportunity to play with the fear evoked by the stereotype of black men as primitive, dangerous and out of control. He expressed his actions as strategic and his ethical goods the ability to play an oppressive system for his immediate gain. His choice to use the stereotype, while promoting his self interest, offered a risky and contingent power. In other words, for members of oppressed groups, playing into stereotypes poses the danger of emplacing, rather than displacing, social group positions. Nonetheless, his and others narratives of resistance to whiteness also gave complexity to the framing of students of color either as victims or objects, or as agents completely in control of their own lives in an equal society. Resistant narratives also introduce contingencies into ethical frames of good and bad individual behavior against the backdrop of representation of group identities.

Tatum (1997), Kirk and Okazawa-Rey (2010) and others have situated dialogues on identity among college students in questions of avowal ("Who am I?" "Who do I want to be?") and ascription (“Who do others say I am or who I should be?”). These are compelling questions for cultural performances of dialogue, and certainly provide an important bridge to discussions of social group identity. A strong goal and challenge of social justice education rests in the definition of the self as both understandable and changeable. We are told to define ourselves and to place boundaries on who we are and are not. And yet, the concept of the self and of identity is itself open to dialogue. How/can we stand in our positions while blurring the boundaries of self and other? More to the point, how can those who have more racial capital work to deterritorialize structural as well as their own and others' whiteness? 


\section{$\underline{\text { Conclusion }}$}

This essay has sought to examine the ways communication ethics might inform dialogue models as well as the facilitation of narratives about identity in dialogue. I chose to look both to theory and at practice, in order to look at assumptions perspectives on dialogue make about the role of power and discourse in constructing identity. My curiosity about the communication of ethics in these models emerged from experience training, being trained, facilitating and observing hundreds of dialogues on race and whiteness among mixed and affinity groups ranging from high school students to university faculty and staff. As such I have a pragmatic interest in improving or expanding the ways we enter into conversations about identity, and about racial identities in particular. An examination of the ways we protect and promote what we believe is good offers one way into understanding difference and the power of moral reasoning. I hope to offer the dialogue facilitator, or those of us in communication who wish to engage in dialogues toward social change, a practical route into such conversation, while also posing larger questions about the certainty with which we engage the concept of "identity".

The discussion of communication ethics and intergroup dialogue necessitates a look at the "shoulds" and "oughts" and the frames for resistance to whiteness discussed throughout this paper. The importance I've assigned to the good of dialogue is overshadowed at times by the urgency with which we (dialogue facilitators) protect and promote the good of talking about the power of whiteness as a structural force. On my campus, self-aware and honest discussion of racial inequities does not emerge 
organically. The (im)morality of whiteness protects an ethical code made up of stories of equality, individuality and personal merit as the means to ending racial injustice.

Herein lies my own ambivalent "should." McLaren reminds us that, " people don't inhabit cultures and social classes, but live out culture or class relations, some of which may be dominant and some of which may be subordinate." [emphasis in original] (75). McLaren's point is that the discursive dynamics of power are always enacted in relation to others. Culture and class are not static categories, but are constantly mutating in and through our everyday interactions. Facilitators and educators concerned with social justice should not stand on the sidelines and hope that dialogue will emerge from good intentions and good will. Yet, I don't think we can reasonably hope to convince those who use their social and cultural capital (un)knowingly to dismantle whiteness and racism solely through our passionate and well-articulated theories about why students who are members of dominant groups are privileged. Models for dialogue that consider communication ethics must consider what our students' stake is in our stories of what "goods" are worth preserving and protecting. How might the discourses we use reflect similar experiences of marginalization, or of pain? How might they also contain underlying interests and concerns for the future that we share? We must utilize dialogism to acknowledge what's at stake in their and our hopes for a good life and better future. For facilitators this might involve identifying our position in and relation to social groups before moving from social justice identity models of dialogue to meta discursive reflection on how these identifications mean, in our everyday performances of who we are. 
In their essay on institutional(izing) merit and white privilege in Communication and the academy, Jackson II and McDonald (2019), observe that white people often treat racism as if they were driving past an automobile accident. "Despite the momentary gasp or the instinct telling you that this is not okay or that people might be hurt, you have to get to wherever it is that you are going" (65). Even for those white people who are well-intentioned, the event is soon forgotten amidst other distractions. However, people of color, who experience the accident directly, are forced to replay the incident repeatedly and in detail. "They must grapple with the aftermath. The violence leaves emotional and psychological residue that may continue to traumatize those involved over and over again. . . The most egregious act, besides the act of violence itself, is the reinstatement of that violence through white silence" (66).

Their analogy points to the urgent need for communication theorists and scholars of privilege to acknowledge the failure of professional ethical codes to take a standpoint as relational beings in dialogue. I am defined and have a career as a white, tenured, professor in relation to those who have not met the culturally- exclusive standards of academia, the discipline and my institution. I am not "lucky." Miller (2019) observes that, "[by] setting up the rules for inclusion in such a way that only those who fit within or are similar to the dominant group can be included and then using these similarities as the very definition for merit within the system, the order represented by the system is maintained." I have worked throughout my career, perhaps somewhat clumsily and always with trepidation, to acknowledge my accountability in the system and to try to disrupt its norms. I have likely hurt as many as I've helped in my endeavors to confront my own and others' whiteness. We (I) must ad- 
vance a communication ethics of the good that does not maintain current systems of exclusion and that troubles notions of civility and merit. We (I) must stand up and support stories that acknowledge the history and current practices of exclusion in order to advance an ethics for living a "good" life. This call to action and activism means that we (especially those of us with societal and institutional privilege) must commit to theorizing communication relationally, regarding settled notions of, for instance, diversity, recognition, as a privileged common sense.

Ivie (2012) argues from the basis of Burke's notion of hierarchies of equality that ethical dialogue does not demand a condition of sameness devoid of gradations of power, position, and privilege or differences of identity, but works to reduce, radical Otherness by articulating hierarchical relations in terms of complementarities and interdependencies within a context of agonistic pluralism. Otherwise, a discourse of equality would prove incompatible with the tenets of liberal democracy, which require a strong regard for individualism no less than, if not more than, community. (379-380) Articulating complementarities and interdependencies in a multi-ethnic and multiracial public sphere implies not only the recognition of the right to express one's difference but, as Meer \& Madood (2010) contend, "the subordinate right to be understood" (358). Our approaches to and facilitation of dialogue play a crucial role in this tenuous balance of discourses and dynamics. The right to be understood, heretofore expressed as white entitlement, implies all the labor and discomfort of learning required of equal partners in dialogue. Where the call to dialogue has often meant invitations to speak, act and be "civil" in accordance with white, middle class cultural 
norms, our models for dialogue must begin with an open discussion of racial and cultural conversational norms and ideas about what might be "good" about doing dialogue differently. If narrative protects and promotes a given good, and our goods must necessarily be in tension, then we must discern paths to go on together in-relation-to one another, holding each other responsible and accountable for the ethical goods that we produce together.

To enter into dialogue with another is to be accountable to the other dialogically (Levinas, 1987). Specifically, as participants in dialogue we must both acknowledge the different locations from which our stories of the good emerge and what is created in that convergence. To be in dialogue with another is not to "lose" oneself but to recognize that position and certainty are created in narrative performance and as such can be open to change. "Difference" in dialogue can be seen not as a threat but an opportunity for learning-learning that is a necessity for mutual survival and ethical actions in a changing world. 
References:

Allen, B. J. (2014). Communication, diversity and ethics in higher education. In R. Arnett \& P. Arneson (Eds.), Philosophy of Communication Ethics, (pp. 97-102). Lanham, MD: Rowman and Littlefield.

Arendt, H. (1998). The human condition (2nd ed).Chicago: University of Chicago Press (Original edition published in 1958).

Arnett, R. C. \& Arneson, P. (1999). Dialogic civility in a cynical age: Community, hope and interpersonal relationships. Albany: SUNY Press.

Arnett, R.C., Fritz, J. M. H., \& Bell, L. M. (2009). Communication ethics literacy. Thousand Oaks, CA: Sage.

Benhabib, S. (1992). Situating the self: Gender, community and postmodernism in contemporary ethics. New York: Routlegde.

Berila, B. (2016). Integrating mindfulness into anti-oppression pedagogy: Social justice in higher education. NYC: Routledge.

Bohm, D., Factor, D. and Garrett, P.(1991). Dialogue-A Proposal. http://www.davidbohm.net/dialogue/dialogue proposal.html. (accessed November 4, 2018).

Buber, M. (1965). Between Man and Man (M. Friedman, Ed.; R.G. Smith, trans). New York: Macmillan.

Coates, T. (2017). Ta-Nehisi Coates on words that don't belong to everyone. YouTube video. https://youtu.be/Q015S3WC9pg

Chesler, M., Lewis and Crowfoot (2005) Challenging racism in higher education: Promoting social justice. Rowman and Littlefield Press. 
Freire, P. (1972). Pedagogy of the oppressed. New York: Continuum.

Gerard, G. and Teurfs, L. (1995) Dialogue and organizational transformation. In Kazimierz Gozdz, (ed), Community Spirit: Renewing Spirit and Learning in Business. (pp. 143-53). San Francisco: New Leaders Press.

Habermas, Jürgen. 1984. Reason and the Rationalization of Society, Volume 1 of The Theory of Communicative Action, English translation by Thomas McCarthy. Boston: Beacon Press (originally published in German in 1981).

Herakova, L., Jelaca, D., Sibii, R. \& Cooks, L. (2011). Voicing Silence and Imagining Citizenship, Communication Studies, 62 (4), 288-319).

Huang Nissen, S. (1999). Defining the principles of dialogue. In Dialogue groups: $A$ practical guide to facilitate diversity conversations (11-12). Blue Hill, ME: Medicine Bear.

Ivie, R. (2010). Hierarchies of equality: Positive peace in a democratic idiom. In The Handbook of Communication Ethics, George Cheney, et al., (Eds.). Routledge. Jackson, R. L. II \& McDonald, A. (2019). The violence of White entitlement and the hypocrisy of earned Merit, Departures in Critical Qualitative Research, 8 (4), 6468. DOI: $10.1525 /$ dcqr.2019.8.4.64

Johnson, A.(2005). Privilege, power and difference. McGraw-Hill.

Kirk, G., \& Okazawa-Rey M. (2010). Identities and Social locations: Who am I? Who are my people? In M. Adams, W. Blumenfeld, C Castaneda, H. W. Hackman, M. L. Peters, X. Zuñiga (Eds.), Readings for diversity and social justice (pp. New York: Routledge.

Levinas, E. (1987). Time and the other. (R. Cohen, Trans). Pittsburgh, PA: Duquesne 
University Press.

Lipsitz, G. (1998). The possessive investment in whiteness. Philadelphia: Temple University Press.

McLaren, P. (2002). Critical pedagogy: A look at the major concepts. In Antonia Darder et al. (Eds.), The critical pedagogy reader (pp. 69-96). New York and London: Routlege/Falmer.

McNamee, S. \& Shotter, J. (2004). Dialogue, creativity and change. In R. Anderson, L.A. Baxter and K. N. Cissna (Eds), Dialogue: Theorizing difference in Communication studies (pp. 91-103). Thousand Oaks: Sage

McIntosh, P. (1990). White privilege: Unpacking the invisible knapsack. Philadelphia, PA: Independent School.

Meer, N. \& Madood, T. (2010). Diversity, Identity, and Multiculturalism in the Media: The Case of Muslims in the British Press. In Cheney, et al.(Eds.), The Handbook of Communication Ethics (pp. 355-374). New York: Routledge.

Miller, L. (2019). Meritocracy and the Maintenance of Order, Departures in Critical Qualitative Research, 8 (4), 76-81. DOI: 10.1525/dcqr.2019.8.4.76

Nagda, R.A. (2006). Breaking barriers, crossing boundaries, building bridges: Communication processes in intergroup dialogues. Journal of Social Issues, 62, 553-576. National Communication Association. "NCA Credo for Ethical Communication." https://www.natcom.org/sites/default/files/pages/1999 Public Statements NCA Credo for Ethical Communication November.pd

Pearce, W. B. and Cronen, V. (1980). Communication, action and meaning: The creation of social realities. New York: Praeger. 
Pearce, K.A. and Pearce, W.B. (2001). The Public Dialogue's Consortium's school-wide dialogue process: A communication approach to develop citizenship skills and enhance school climate. Communication Theory, 11, 105-123.

Pearce, W. B. and Pearce, K. A. (2004). Taking a communication perspective on dialogue. In R. Anderson, L.A. Baxter and K. N. Cissna (Eds), Dialogue: Theorizing difference in Communication studies (pp. 39-56). Thousand Oaks: Sage.

Peters, J. D. (1999). Speaking into the air: A history of the idea of communication. Chicago: University of Chicago Press.

Rodriguez, J., Nagda, R.A., Sorenson, N., \& Gurin, P. (2018). Engaging race and racism for socially just intergroup relations: The impact of intergroup dialogue on campuses in the U.S. Multicultural Education Review, 10(3), 224-245. doi: 10.1080/2005615X.2018.1497874

Stewart, J., Zediker, K. E. and Black, L. (2004). Relationships among philosophies of dialogue. In R. Anderson, L.A. Baxter and K. N. Cissna (Eds), Dialogue: Theorizing difference in Communication studies (pp. 21-38). Thousand Oaks: Sage.

Tatum, B. D. (1997). Why are all the Black kids sitting together in the cafeteria? And other conversations about race. New York: Basic Books.

Taylor, (2004). Dialogue as the search for sustainable organizational co-orientation. In R. Anderson, L.A. Baxter and K. N. Cissna (Eds), Dialogue: Theorizing difference in Communication studies (pp. 125-140). Thousand Oaks: Sage.

Wise, T. (2010). Colorblind: The rise of post-racial politics and the retreat from racial equity. City Lights Publishers. 
Zuñiga, X., Nagda, B., Chesler, M. \& Cytron-Walker, A. (2007). Intergroup Dialogue in Higher Education: Meaningful learning about Social Justice. ASHE Higher Education Report: 32,(4).

Zuñiga, X. (2010). Five College Facilitator training: Intergroup dialogue. University of MA, Amherst.

Endnotes

${ }^{1}$ Here and throughout the paper "we" refers to the facilitators and myself/author.

2 Today, students in the social sciences on our campus will encounter more curricula on the topic of race, but they continue to report few to no opportunities for intergroup dialogue.

3 Acronym common on our campus then for African-American, Latin-American, AsianAmerican and Native American students

${ }^{4}$ It should be noted that one or two white-appearing students sat in groups with students of color, and several students who identified as students of color (and one Asian American student who identified as white) sat with white groups.

${ }^{5}$ Due to space considerations I provide only a brief summary of these complicated dynamics in this paper. 